\title{
Decolourization of Anthraquinone Reactive Dye by Electrochemical Reduction on Reticulated Glassy Carbon Electrode
}

\author{
Patricia A. Carneiro, Nivaldo Boralle, Nelson R. Stradiotto, Maysa Furlan and \\ Maria Valnice B. Zanoni*
}

Instituto de Química, Universidade Estadual Paulista , CP 355, 14801-970 Araraquara - SP, Brazil

\begin{abstract}
A remoção do corante reativo Reactive Blue 4 (RB4) por redução eletroquímica em solução aquosa foi investigada sobre eletrodo de carbono vítreo reticulado. O grupo antraquinona presente no corante $\mathrm{RB} 4$ é reduzido em $\mathrm{pH}<8,0$ em uma única etapa a hidroquinona, segundo um processo reversível de dois elétrons e reação de pré-protonação, via geração de um radical semiquinona detectado espectrotométricamente. $\mathrm{Em} \mathrm{pH}>8,0$, ambas as formas não e pré-protonada da antraquinona são reduzidas em duas etapas reversíveis de dois elétrons. Após 3 horas de eletrólise em meio ácido e neutro o corante perde $60 \%$ de sua coloração, enquanto que em meio alcalino perde apenas $37 \%$. Simultaneamente, $64 \%$ de remoção de carbono orgânico total foi obtida após eletrólise em meio ácido de $\mathrm{pH} 2,0$.
\end{abstract}

The electrochemistry reduction for the removal of Reactive Blue 4 (RB4) dye from aqueous solution using reticulated glassy carbon electrode is investigated. At $\mathrm{pH}<8.0$ the anthraquinone group of the RB4 dye are reduced in one cathodic step to hidroquinone after a reversible two-electron process involving a precedent two protons reaction. A stable semiquinone is detected by spectrophotometric technique. At $\mathrm{pH}>8.0$ the reduction process involves two reversible 2-electron steps, whose species are generated by a protonation equilibrium of anthraquinone group. The results shows that $60 \%$ of color removal was obtained after 3 hours of RB4 dye electrolysis at acidic and neutral conditions and only $37 \%$ at alkaline conditions. Simultaneously $64 \%$ of total organic carbon was removed after electrolysis at $\mathrm{pH} 2.0$.

Keywords: reactive dyes, electrochemical reduction, dye treatment, reactive blue 4

\section{Introduction}

Reactive dyes are the main group of dyes used in the textile industry. ${ }^{1}$ They are very effective in fabric dyeing due to the reactive groups capable of forming covalent bonds with a hydroxyl or amino group on the fiber. Inefficiencies in the dyeing process results in $10-15 \%$ of all dyestuff being lost directly to wastewater. ${ }^{2}$ Therefore, their crescent world consumption has attracted the critical attention of the public and the authorities with respect to the toxicological and environmental aspects of the reactive dyes. ${ }^{3,4}$

Dye wastewater is usually treated by physical or chemical treatment process. They include physicalchemical flocculation, electroflotation, membranefiltration, electrokinetic coagulation, ion-exchange, irradiation, precipitation and other treatment using

* e-mail: boldrinv@iq.unesp.br activated carbon. ${ }^{5}$ Over the past few years, alternative methods $^{6-10}$ for dye treatment have been investigated, including chemical oxidation with reagents such as: ozone, hydrogen peroxide, ozone/UV, hydrogen peroxide/UV and Fenton's reagent [hydrogen peroxide $+\mathrm{Fe}$ (II)]. The application of electrochemical oxidation with or without UV light as method for dye degradation have also been investigated, ${ }^{11-15}$ but no mechanisms of the reduction were discussed. ${ }^{16-19}$ Most of the electrochemical studies involving reduction of reactive dyes are based on mercury electrode $^{16-19}$ and the decolorization and mineralization by electrochemical treatment are less studied.

Anthraquinone base dyes are very resistant to degradation due to their fused aromatic structures, low biodegradability and thus remain colored for a longer time in the wastewater. So, a corresponding increase in the use of this class of reactive dye has highlighted the need to know not only the possibility of color removal of the dye by electrochemical methods but also understand its 
electrochemical behavior and possible products generated. Reactive Blue 4 (RB4) dye (C.I. 61205) is an anthraquinone based chlorotriazine reactive dye extensively used in dyeing, which chemical structure is shown in Figure 1. The main processes described in the literature for RB4 dye are based only on photodegradation experiments, ${ }^{20-23}$ but no electrochemical study was described.

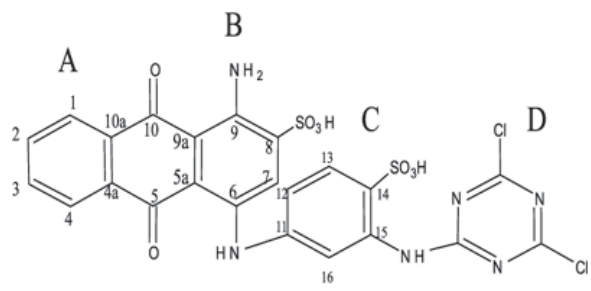

Figure 1. Molecular structure of the Reactive Blue 4 dye (RB4). A and B (cromophore group); (C) spacer and (D) dichlorotriazine group.

In this paper we investigated the electrochemical reduction of the (RB4) in aqueous solution on a carbon electrode. The feasibility of color removal and dye degradation by controlled potential electrolysis was evaluated using reticulated glassy carbon electrode.

\section{Experimental}

The electrochemical measurements were carried out using a Potentiostat/Galvanostat EG\&G PARC model 283 controlled by the Electrochemical 270 software. The cell used for cyclic voltammetric experiments was of a threeelectrode type, with two compartments. The working electrode was a glassy carbon (PARC) disc, area $0.28 \mathrm{~cm}^{2}$, polished between experiments. A carbon auxiliary electrode and an $\mathrm{Ag} / \mathrm{AgCl}\left(3.0 \mathrm{~mol} \mathrm{~L}^{-1}\right)$ electrode were used as the counter and reference electrodes, respectively. The controlled potential electrolysis were carried out using a three compartment cell, where a reticulated vitreous carbon electrode (area $2.5 \mathrm{~cm}^{2}$ ), separated by a fine glass sinter, acted as cathode and a $4.0 \mathrm{~cm}^{2} \mathrm{Pt}$ gauze acted as anode in the other compartment.

The dye degradation was conducted by aliquots transference of RB4 dye solution submitted to different time of electrolysis at defined experimental conditions. TOC and color of the solution were measured using the Total Organic Carbon Analyzer (Shimadzu 5000A) and a diode array UVVis spectra recorded at a HP 8453 spectrophotometer operating from 190-1000 nm in quartz cell. The products generated after total electrolysis were also analyzed using previous solid-phase extractions. A Waters Associates SepPack C18 cartridge was pre-washed with ethanol, water and ethanol. Aliquots of the electrolyzed sample were diluted with water and passed through the cartridge. Elution of the products was effected with ethanol. The solvent was evaporated in a freeze dry system Labconco Frezone. The products were checked by IR spectroscopy in a spectrometer Nicolet - Impact 400. and NMR spectroscopy in a spectrometer Nuclear Magnetic Ressonance INOVA-500 at $500 \mathrm{mHz}$. Deuterated methanol was utilized as solvent and TMS as the internal standard.

All pH measurements were made with a Corning 555 pHmeter with a glass electrode, which had been calibrated previously. Supporting electrolytes and stock solutions were prepared in desmineralized water from a Milli-Q system (Millipore). Stock solutions of RB4 were prepared from solid samples obtained from Aldrich. The studies were carried out in Britton-Robinson (B-R) buffer $\left(0.04 \mathrm{~mol} \mathrm{~L}^{-1}\right.$ in each of acetic, ortho-phosphoric and boric acids) adjusted to the required $\mathrm{pH}$ with $0.2 \mathrm{~mol} \mathrm{~L}^{-1}$ sodium hydroxide solution.

\section{Results and Discussion}

Voltammetric behavior of the RB4 dye

The reduction of RB4 was studied in B-R buffer $\mathrm{pH}$ 2.0 - 12. Typical cyclic voltammograms obtained for $1.0 \times 10^{-3} \mathrm{~mol} \mathrm{~L}^{-1} \mathrm{RB} 4$ dye in $0.04 \mathrm{~mol} \mathrm{~L}^{-1}$ Britton-Robinson (B-R) buffer at $\mathrm{pH} 4.5,7.0$ and 11 are shown in Figure $2 \mathrm{a}$, $\mathrm{b}$ and $\mathrm{c}$, respectively. Only one well-defined reduction peak was seen at $\mathrm{pH}<8.0$, but the cyclic voltammograms exhibited two well defined reduction peaks in alkaline solutions. Plots of peak potential vs. $\mathrm{pH}$ peak current $v s$. $\mathrm{pH}$ are shown in Figure 3. The peak currents have shown neglected variation but the peak potentials of the first reduction process (I) shifted toward more negative values with increasing $\mathrm{pH}$ up to $\mathrm{pH} 8.0$ by $54.6 \mathrm{mV}$ per $\mathrm{pH}$ unit (Segment A, Figure 3). This indicates that hydrogen ions are involved in the electrode reaction. Based on the $n=2$ $\left(\mathrm{n}=\right.$ electron number) value, obtained from $\mathrm{Ep}-\mathrm{E}_{1 / 2}=47.7$ $\mathrm{mV}$ values of cyclic voltammograms in acidic medium, the number of protons involved are $2\left(\mathrm{~m}_{\mathrm{H}+}=1.85\right)$. At $\mathrm{pH} \mathrm{t}$ 8.0 two reduction process are seen (segment $\mathrm{B}$ and $\mathrm{C}$, Figure 3). The first peak have shown a linear relationship from $\mathrm{E}_{\mathrm{p}} v s . \mathrm{pH}$, but the slope becomes equal to $35.4 \mathrm{mV}$ per $\mathrm{pH}$ unit at higher $\mathrm{pH}$ values, suggesting that only one proton is involved when $\mathrm{m}_{\mathrm{H}+}=1.2$. An inter or intra molecular rearrangement involving amino group close to carbonyl group present in anthraquinone group could be responsible for reduction of the quinone group in a protonated form even in alkaline medium. ${ }^{24}$ At $\mathrm{pH}>8.0$, the second wave presents a relationship where the peak potential (II) is independent of $\mathrm{pH}$ suggesting the 

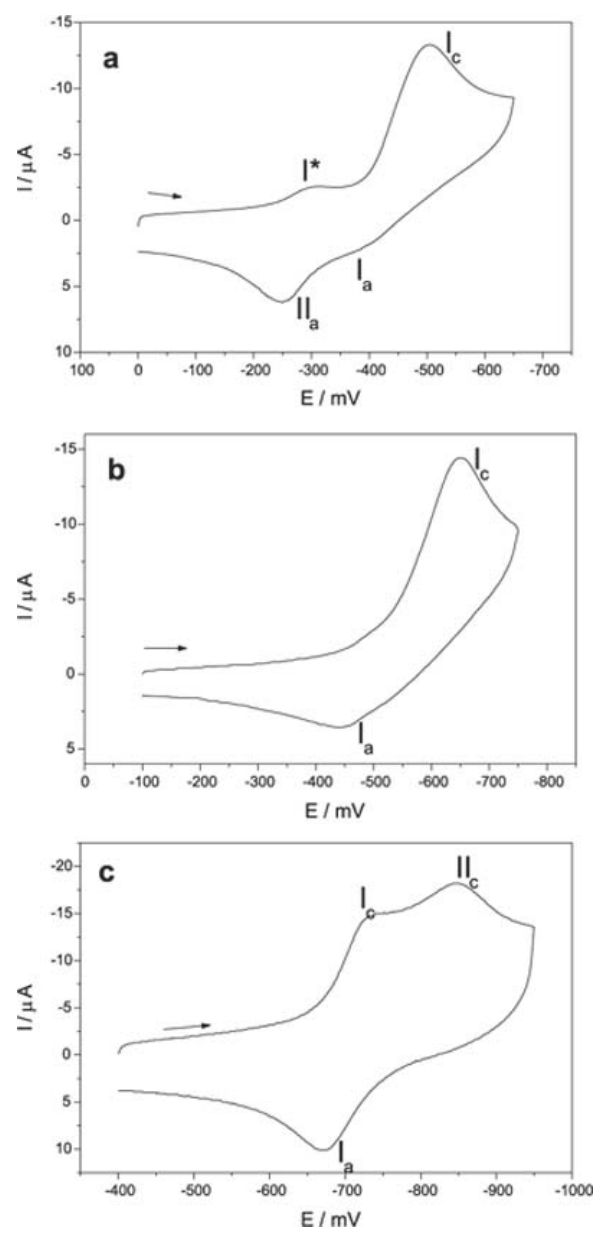

Figure 2. Cyclic voltammograms of RB4 dye reduction $1.0 \times 10^{-3}$ mol L-1 in glassy carbon electrode, $v=0.05 \mathrm{~V} \mathrm{~s}^{-1}$ in a $0.04 \mathrm{~mol} \mathrm{~L}^{-1}$ B-R buffer at (a) $\mathrm{pH} 4.5$; (b) $\mathrm{pH} 7.0$ and (c) $\mathrm{pH} 10$.

occurrence of an electrodic process without preprotonation reaction.

At acidic medium (Figure 2a) is reduced in one main reduction cathodic process (peak $\mathrm{I}_{\mathrm{c}}$ ) and two anodic peaks are shown in the reverse scan $\left(\mathrm{I}_{\mathrm{a}}\right.$ and $\left.\mathrm{II}_{\mathrm{a}}\right)$. The cathodic peak increases linearly with $v^{1 / 2}$, indicating an diffusion controlled process. When the scan rate is increased is observed that the ratio of the $\mathrm{I}_{a} / I_{c}$ peak heights increases, the peak I increases concomitantly with the decreasing in the peak II, showing the behavior where the electrodic process involves a chemical reaction that consumes the product generated after the electron transfer $\left(\mathrm{I}_{\mathrm{a}}\right)$. The reoxidation product generated due chemical reaction occurs at less negative potential (II $)$. A variation in $\mathrm{E}_{\mathrm{p}}$

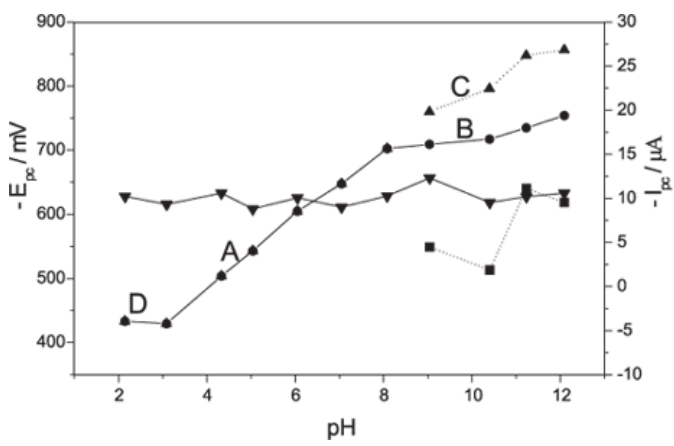

Figure 3. Influence of $\mathrm{pH}$ variation on the peak potentials [Curve $(--)$ and $(-\mathbf{\Delta}-)$ ] and peak current [Curve $(-\boldsymbol{\nabla}-)$ and (一—)] obtained from cyclic voltammograms of reduction $1.0 \mathrm{x}$ $10^{-3} \mathrm{~mol} \mathrm{~L}^{-1} \mathrm{RB} 4$ dye in a B-R buffer. $\mathrm{n}=0.05 \mathrm{~V} \mathrm{~s}^{-1}$.

with an increase in the scan rate $\left(\Delta \mathrm{E}_{\mathrm{p}} / \Delta \log v\right)=32.5 \mathrm{mV}$ and $\left(\Delta \mathrm{E}_{\mathrm{p}} / \Delta \log \mathrm{C}\right)=0 \mathrm{mV}$ was also observed. Moreover, the cathodic current functions $\left(\mathrm{I}_{\mathrm{p}} \cdot v^{-1 / 2} \cdot \mathrm{C}\right)$ increased with the scan rate. This behavior is indicative of multiple electron transfer sequence in which the product of charge transfer undergoes a chemical reaction yielding an electrochemically active specie more readily reduced than the parent compound. ${ }^{24,25}$ The occurrence of a small peak at less negative potential $\left(I_{c}\right)$ is seen at acidic conditions, which intensity is always very small and disappear at $\mathrm{pH}$ t 6.0, as shown Figure 2a. At very acidic condition $(\mathrm{HCl} / \mathrm{KCl} \mathrm{pH} 2.2)$, the main reduction process is followed by two other peaks at very negative potential $(\mathrm{III}=-0.9 \mathrm{~V}$ and $\mathrm{IV}_{\mathrm{c}}=-1.0 \mathrm{~V}$ ), as shown Figure 4 . The first peak has the same behavior described previously in B-R buffer but the other two peaks present a shifted in the peak potential increasing the scan rate and the current function (Ip. $v^{-1 / 2}$.C) decreases with scan rate showing the participation of subsequent chemical reaction to the electron transfer. At neutral conditions (Figure 2b) the behavior is similar to that observed at less acidic condition,

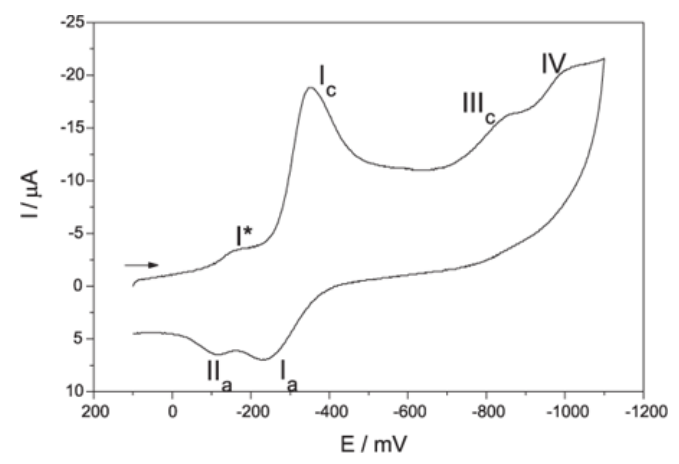

Figure 4. Cyclic voltammograms of $1.0 \times 10^{-3} \mathrm{~mol} \mathrm{~L}^{-1} \mathrm{RB} 4$ dye reduction in a glassy carbon electrode, in a $0.2 \mathrm{~mol} \mathrm{~L}^{-1} \mathrm{HCl} / \mathrm{KCl}$ solution at $\mathrm{pH}$ 2.2. $v=0.05 \mathrm{~V} \mathrm{~s}^{-1}$. 
except for the absence of pre-peak in the cyclic voltammograms and peak II in the reverse scan.

At alkaline medium the voltammetric behavior shows two reduction peaks in the $\mathrm{pH}$ range of $8.0<\mathrm{pH}<12$, and only one in the reverse scan $\left(\mathrm{I}_{\mathrm{a}}\right)$, as shown Figure 2c. The effect of scan rate on cyclic voltammograms covering both reduction peaks at $\mathrm{pH} 11$ was studied. The peak current for both peaks were proportional to $v^{1 / 2}$ indicating that both electrodic processes are diffusional controlled. The peak $\mathrm{I}_{\mathrm{c}}$ exhibits an anodic peak in the reverse scan $\left(\mathrm{I}_{\mathrm{a}}\right)$. The ratio of the anodic-to-cathodic peak heights $\left(\mathrm{I}_{\mathrm{a}} / \mathrm{I}\right)$ is around 0.95 . The current function and peak potential are independent of scan rate, indicating that the process involves a reversible electron transfer. The second peak $\mathrm{II}_{\mathrm{c}}$ does not show any reoxidation peak. The cathodic peak shifts to negative potential and the current function increases with scan rate, indicating a mechanism where chemical reaction are coupled at multiple electron transfer. ${ }^{25,26}$

\section{Controlled potential electrolysis}

All reductions were carried out on $0.04 \mathrm{~mol} \mathrm{~L}^{-1}$ solutions in B-R buffer $\mathrm{pH} \mathrm{4.5,} 7.0$ and 10 and $\mathrm{pH} 2.2$ in $\mathrm{HCl} / \mathrm{KCl}$ solution using a reticulated vitreous carbon electrode. In each case, the electrolysis was performed at a potential more negative than the reduction peak recorded on these electrode. The current was recorded as a function of time and the number of electrons (n) consumed in the total reduction was determined (Table 1). In acidic medium $\mathrm{pH} 4.5$ the current decays linearly with time and the n-values obtained are around 2 electrons $(1.88 \pm 0.40$ with 3 repetitions $)$ and this value increases slightly in neutral solution. Nevertheless, at alkaline condition the current also decays linearly but the $n$ values obtained were around $5(n=5.46 \pm 0.25$ with 3 repetitions) indicating that the two reduction processes are occurring simultaneously. At very acidic conditions $(\mathrm{HCl} /$ $\mathrm{KCl} \mathrm{pH} \mathrm{2.2)} \mathrm{the} \mathrm{current} \mathrm{decays} \mathrm{linearly} \mathrm{at} \mathrm{the} \mathrm{start} \mathrm{of} \mathrm{the}$ electrolysis but increases again close to the end of the electrolysis, where an extra consumption of electricity is detected. The $\mathrm{n}$ values obtained were around 6 electrons ( $\mathrm{n}$ $=6.18 \pm 0.10$ ). This behavior could be interpreted as the effect of a secondary chemical reaction or other sites of the

Table 1. Coulometric results obtained by controlled potential electrolysis of the dye RB4 at reticulated glassy carbon electrode

\begin{tabular}{lccccccc}
\hline $\mathrm{pH}$ & time $(\mathrm{h})$ & $-\mathrm{E}(\mathrm{V})$ & $\mathrm{n}_{\text {ap1 }}$ & $\mathrm{n}_{\text {ap2 }}$ & $\mathrm{n}_{\text {ap3 }}$ & $\overline{n_{a p}}$ & $\mathrm{SD}$ \\
\hline $2.2^{\mathrm{a}}$ & 2 & 0.600 & 6.07 & 6.20 & 6.27 & 6.18 & \pm 0.10 \\
$4.5^{\mathrm{b}}$ & 3 & 0.700 & 1.94 & 1.45 & 2.25 & 1.88 & \pm 0.40 \\
$7.0^{\mathrm{b}}$ & 3 & 0.850 & 3.00 & 3.07 & 2.49 & 2.85 & \pm 0.32 \\
$10^{\mathrm{b}}$ & 4 & 0.900 & 5.17 & 4.97 & 5.46 & 5.20 & \pm 0.25 \\
\hline
\end{tabular}

${ }^{\mathrm{a}} \mathrm{HCl} / \mathrm{KCl}$ solution; ${ }^{\mathrm{b}} \mathrm{B}-\mathrm{R}$ buffer; $\overline{n_{a p}}=$ average values of $\mathrm{n}_{\mathrm{ap}}$. molecule are reducing after long time of electrolysis, such as the reduction of chlorotriazine group. ${ }^{16,17,28}$

At the end of the electrolysis the products at the cathode were examined by UV-VIS spectrophotometry and IR and NMR spectroscopy. ${ }^{27}$ The UV-VIS spectrum obtained for $\mathrm{RB} 4$ dye in $\mathrm{pH} 2.2$ before electrolysis is shown in Figure 5 (Curve I). The spectra obtained at $\mathrm{pH} 2.2,4.5$ and 7.0 are similar. The correspondent spectrum displayed absorption bands at $595 \mathrm{~nm} ; 370 \mathrm{~nm}$ and $296 \mathrm{~nm}$ characteristics of the anthraquinone group. The another peak at $256 \mathrm{~nm}$ is attributed to the aromatic character and chlorotriazine group. The UV-VIS spectrum after the electrolysis shows the accentuated decreasing of the anthraquinone group, displaying absorption band only at $256 \mathrm{~nm}$ and new peak at $475 \mathrm{~nm}$ (Figure 5, Curve II). During the electrolysis is possible to see the change of original blue color to yellow one, which disappears after long time in solution. The blue color of RB4 dye is generated by the electron-donating substituents such as $-\mathrm{NH}_{2}$ and $-\mathrm{NH}$-Ar forming hydrogen bond with $-\mathrm{C}=\mathrm{O}$ bond within the molecule. In general, when there are some modifications in this electron-donating substituents to keep the heavy electron cloudy is difficult, therefore the chemical compound appears to be yellow. This may explain the formation of the yellow intermediate.

The formation and disappearing kinetics as shown in Figure 5 has a typical intermediate character, since this signal is completely extinguished after a rest of 10 hours in solution (Figure 5, Curve III). The IR absorptions at 3445, 1724, 1623, 15721491 and $1407 \mathrm{~cm}^{-1}$ and $880 \mathrm{~cm}^{-1}$ were attributed to a hydroxyl, carbonyl, aromatic and chlorotriazinyl groups, respectively, compatible with the structure of the original dye (Figure 1). The most remarkable difference in the IR absorptions obtained for original dye and its electrolyzed product at $\mathrm{pH} 2.2,4.5$ and 7.0 was the disappearance of the absorptions at $1745 \mathrm{~nm}(\mathrm{C}=\mathrm{O}$ bond $)$ and occurrence of new

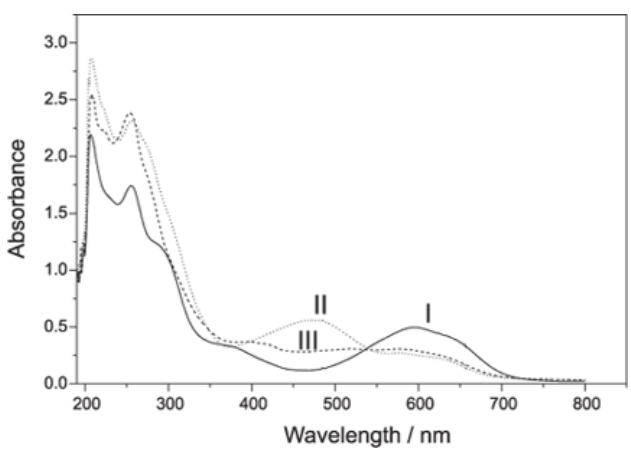

Figure 5. Absorption spectra of $2.5 \times 10^{-4} \mathrm{~mol} \mathrm{~L}^{-1}$ original and electrolyzed $\mathrm{RB} 4$ dye in a $0.2 \mathrm{~mol} \mathrm{~L}^{-1} \mathrm{HCl} / \mathrm{KCl}$ solution at $\mathrm{pH} 2.2$ (I) (一) before electrolysis; (II) (...) after controlled potential electrolysis at $\mathrm{E}=-0.60 \mathrm{~V}$ for $3 \mathrm{~h}$ (after immediate remotion); (III) $(-)$ after $10 \mathrm{~h}$ in solution. 
band at $1121 \mathrm{~cm}^{-1}$ (C-OH bond), indicating the reduction of carbonyl group from quinone group and generation of hydroquinone. The disappearance of band at $881 \mathrm{~cm}^{-1}$ attributed to the chlorotriazinyl group is observed only at $\mathrm{pH} 2.0$, indicating that the probable cleavage of the reactive group is occurring at this $\mathrm{pH}$ value.

The most remarkable difference in the NMR spectrums of the products generated after electrolysis in acidic and alkaline medium when compared with original spectrum NMR of the RB4 dye were the modifications observed in the aromatic ring $\mathrm{C}$ (Figure 1). The unidimensional (H NMR and gNOESY1D) and bidimensional (gCOSY, gHMBC and gHMQC) spectrums of the RB4 dye exhibited signals at $\delta 6.63$ (doublet, $J_{\text {meta }} 2 \mathrm{~Hz}$ ), $\delta 6.50$ (double doublet, $J_{\text {meta }} 2 \mathrm{~Hz}$ and $J_{\text {ortho }} 8 \mathrm{~Hz}$ ) and at $\delta 7.66$ (doublet, $J_{\text {ortho }} 8 \mathrm{~Hz}$ ) that represent the positions H16, H12 and H13 in the aromatic ring $\mathrm{C}$ (Figure 1). The spectrum after electrolysis in alkaline medium $(\mathrm{pH} \mathrm{10)}$ evidence two hydrogens at $\delta 7.56$ and $\delta 7.09$ ( $\mathrm{H} 7$ and $\mathrm{H} 8$ ) that couple with ortho coupling constant equal a $8 \mathrm{~Hz}$, which indicate the presence of aromatic ring $\mathrm{B}$, but in this case, observed the absence of the $\mathrm{SO}_{3} \mathrm{H}$ group in the position 8, which was substituted by hydrogen. After electrolysis in alkaline medium not observed the cleavage of the dye by bond between ring $\mathrm{B}$ and $\mathrm{C}$, because all signals $(\delta 6.63, \delta 6.50$ and $\delta$ 7.61) are observed in the NMR spectrum.

In acidic medium after controlled potential electrolysis the NMR spectrum of the dye confirms the absence of the hydrogen at position 8 (H-8) by disappear of signal in $\delta$ 7.09 suggest that don't exist only one ortho correlation between the H-8 and H-7 and vice and it turns, but the appearance of many signals, indicating cleavage of the bond between $\mathrm{B}$ and $\mathrm{C}$ rings by $\mathrm{C}-\mathrm{N}$ bond. So now the hydrogen at position 6 will interact with hydrogens at position 7 and 8 generating many signals.

The main product obtained after complete electrolysis in alkaline solution ( $\mathrm{pH} \mathrm{10)}$ was also identified by UV-VIS spectrophotometry and the spectrum have shown a decreasing less accentuated in the dye chromophore bands at $589 \mathrm{~nm}$ and $370 \mathrm{~nm}$ than in acidic solution. Concomitantly, the intermediate generated and identified at $489 \mathrm{~nm}$ is not intense. The IR absorption at $867 \mathrm{~nm}$ is still remained, suggesting that there is no cleavage of the reactive group but the occurrence of a band at $1120 \mathrm{~cm}^{-1}$ could be attributed to the deformation of $\mathrm{O}-\mathrm{H}$ bond, suggesting the generation of hydroquinone group.

\section{Reduction of RB4 dye}

The results described above, together with electrochemical information on other similar compounds, ${ }^{1,16,24}$ allow us to attribute the first reduction process of RB4 dye to the reduction of the anthraquinone group that occurs in one single step at neutral and acidic conditions and two reduction steps at alkaline conditions. The reduction of reactive group is observed only at $\mathrm{pH} \mathrm{d} 2$. The main results are represented in Scheme 1.

The anthraquinone group in the RB4 dye is reduced in only one main step of two electrons $\left(\mathrm{E}_{1}\right)$ over the range 2.0 $<\mathrm{pH}<8$.0. From $\mathrm{E}_{\mathrm{p}}$ vs. $\mathrm{pH}$ it is diagnosed an acid-base equilibrium involving $2 \mathrm{H}^{+}$, which is probably associated with the pre-protonation of the quinone group following the equilibrium between $\mathrm{A} \square \mathrm{B}$ species (Scheme 1). Coulometric results confirms that the protonated species are reduced involving the transference of $2 \mathrm{e}^{-}$to form the yielding hydroquinone derivative, which was identified by IR and NMR spectra after complete electrolysis and long time in solution. The formation of stable semiquinone (specie B, Scheme 1) as intermediate was identified by UV-VIS spectrophotometry in acidic and neutral solutions. The slow chemical reaction rate controlling the conversion of semiquinone to hydroquinone is preponderant only at low scan rate and higher $\mathrm{pH}$. Therefore, both species control the difference in the peak intensity of peak $\mathrm{I}_{\mathrm{a}}$ and peak $\mathrm{II}_{\mathrm{a}}$, respectively at the reverse scan on the cyclic voltammograms.

The reduction of the dichlorotriazine groups in the RB4 dye on glassy carbon electrode occurs only at a very negative potential $\left(\mathrm{E}_{2}\right)$ and can be seen in the voltammograms only in $\mathrm{HCl} / \mathrm{KCl} \mathrm{pH} \mathrm{2.2.} \mathrm{As} \mathrm{other}$ compounds containing similar groups ${ }^{16,18,28}$ reduction of the reactive $\mathrm{C}-\mathrm{Cl}$ bond in triazinyl ring requires a preprotonation step followed by a cleavage of the chlorine groups and it is represented as the reaction involving D $\square$ species at the final reduction of the dye (Scheme 1). Coulometric results confirms that in this medium the number of electrons involving increases, where besides the reduction of anthraquinone group the reactive group as also reduced. The loss of reactive group and one sulphonate group from the hydroquinone derivative was also detected by IR and $\mathrm{NMR}^{27}$ analysis.

At alkaline media $(\mathrm{pH}>8.0)$ both species of anthraquinone in a non-protonated form (A) and protonated form $(\mathrm{F})$ are being reduced sequentially in two steps $\left(\mathrm{E}_{1}\right.$ and $\mathrm{E}_{2}$ ). The $\mathrm{E}_{\mathrm{p}}$ vs. $\mathrm{pH}$ relationship confirms that the second electrodic reaction involves a pre-protonation reaction based on 1 proton, which could be attributed to an inter or intra molecular rearrangement involving quinone/amino tautomerism, which is responsible for reduction of the quinone group in a protonated form even in alkaline medium. UV-VIS spectra recorded for the catholyte after total electrolysis show that the absorption band at $489 \mathrm{~nm}$ 
592

Carneiro et al.

J. Braz. Chem. Soc.

$2.0<\mathrm{pH}<8.0$

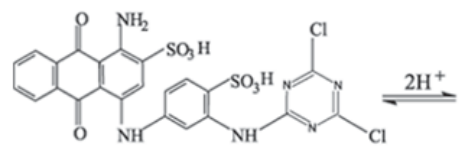

A

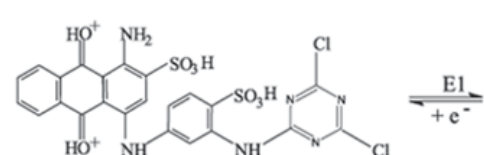

B

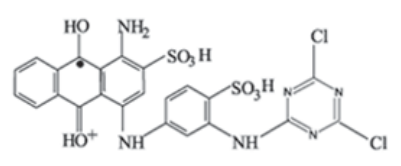

El ${ }_{1}+\mathrm{e}^{-}$

C

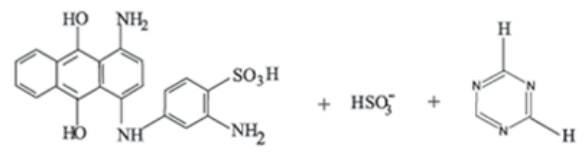

E

$\frac{\mathrm{E} 2}{\substack{2 \mathrm{H}^{+} \\+2 \mathrm{e}^{-}}}$

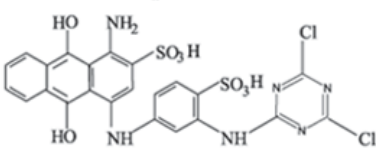

D

pH $\geq 8.0$

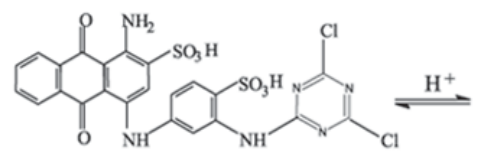

A

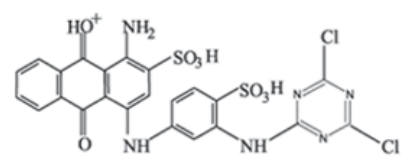

ute

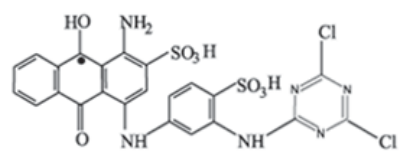

$\mathrm{E} 2 \|+\mathrm{e}^{-}$

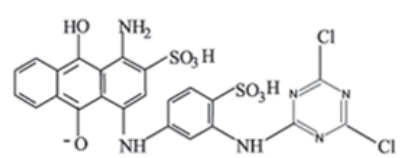

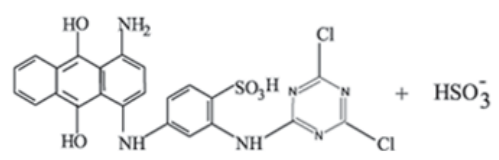

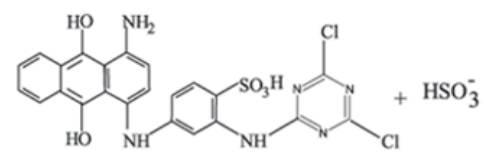

Scheme 1. Reduction Mechanism of Reactive Blue 4. 
due to the intermediate can be observed only after long time of electrolysis (4h), which rapidly is disappeared in solution. This behavior indicates that the semiquinone $(\mathrm{H})$ is more unstable at alkaline conditions. Coulometric results confirms that both species $\mathrm{A}$ and $\mathrm{F}$ are being reduced in two steps involving at least two electrons each. The results are confirmed by cyclic voltammetric studies that indicates the behavior expected for a multiple electron transfer complicated by chemical reactions. The IR and NMR spectra indicates that there is no significative cleavage of the hydroquinone derivative generated except from that observed for lost of one sulphonate group (Scheme 1).

In order to define quantitatively the rate of electroreduction of anthraquinone dyes in reticulated carbon electrode and to follow the dye degradation in aqueous solution, the electrolysis were interrupted and the solutions were examined by spectrophotometric analysis each 15 min up to a maximum of $4 \mathrm{~h}$. Each spectrum were recorded for aliquots of the solution submitted to the controlled potential electrolysis, which were restarted for a new solution under identical conditions. The original dye spectrum is shown in Figure 5, Curve I. RB4 dye obeys the Beer's Law for dye concentrations up to $5.0 \times 10^{-4} \mathrm{~mol} \mathrm{~L}^{-1}$; $\varepsilon=2.06 \times 10^{4} \mathrm{~mol}^{-1} \mathrm{~L} \mathrm{~cm}^{-1}$.

In Figure 6A, performance of the reticulated carbon cathode in color removal is evaluated as Fractional Conversion $(f)$ of the dye and plotted in a time-dependent scale for electrolysis carried out in different $\mathrm{pH}$ values of 2.2, 7.0 and 10. Fractional conversion is the ratio of dye concentration variation at time $\mathrm{t}\left(\mathrm{C}_{\mathrm{t}}\right)$ to the initial dye concentration $\left(\mathrm{C}_{0}\right)$ in solution at $\mathrm{t}=0$. Concentration was determined by monitoring the absorbance of RB4 dye at $\mathrm{O}=595 \mathrm{~nm}$, from the UV-Visible absorption spectra as a function of time. The fractional conversion indicates $61 \%$ removal of color when $50 \mathrm{~mL}$ of the dye is electrolyzed for $120 \mathrm{~min}$. Similar results were obtained at $\mathrm{pH} 7.0$ under $\mathrm{E}=$ $-0.85 \mathrm{~V}$, when $62 \%$ of decolorization are obtained. On the other hand, only $37 \%$ of color removal was observed for electrolysis conducted at $\mathrm{pH} 10$, respectively. A linear relationship of $\ln \mathrm{C} / \mathrm{C}^{\circ}$ vs $\mathrm{t}$ is obtained for both acidic and neutral medium, as shown Figure 6B. In addition, it is observed a deviation from the behavior of a pseudo first
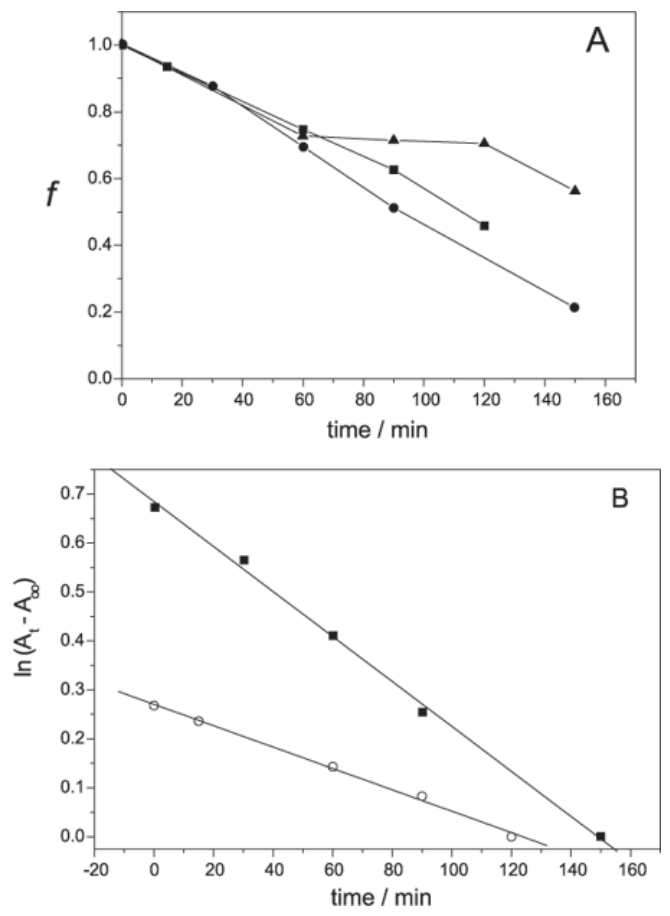

Figure 6. Decolorization of RB4 dye by controlled potential electrolysis at different times of electrolysis. (A) Fractional conversion (一-) $\mathrm{pH} 2.2$ in $\mathrm{HCl} / \mathrm{KCl}$ solution; (- - $\mathrm{DH} 7.0$ in B-R buffer; (一 - - ) $\mathrm{pH} 11$ in B-R buffer. (B) Relationship from ln (A -Af ) vs time for: (- - ) $\mathrm{pH} 2.2$ in $\mathrm{HCl} / \mathrm{KCl}$ solution and $(-\mathrm{O}-) \mathrm{pH} 7.0$ in B-R buffer.

order reaction in dye consumption at alkaline condition. The rate degradation constant $(\mathrm{k})$ obtained from values of $\ln \left(\mathrm{A}-\mathrm{A}_{\mathrm{f}}\right)$ vs time and initial degradation rate $\left(\mathrm{V}_{\text {initial decolorization }}\right)$ are shown in Table 2. These results illustrate that dye degradation by electrolytic reduction is more effective at neutral conditions than acidic condition. At alkaline conditions there is a rapid first stage reduction reaction of the dye which is followed by a much slower reaction. This implies that the first stage of the conversion of the RB4 dye to the semiquinone in the electrochemical process is vital to the successful final of the decolorization of the solution.

Table 2. Results obtained after controlled potential electrolysis in reticulated glassy carbon electrode for RB4 dye at differents pH values

\begin{tabular}{lccccr}
\hline $\mathrm{pH}$ & $\begin{array}{c}1 \\
(\mathrm{~nm})\end{array}$ & $\begin{array}{c}-\mathrm{E} \\
(\mathrm{V})\end{array}$ & $\begin{array}{c}\text { Total time of } \\
\text { electrolysis }(\mathrm{h})\end{array}$ & $\begin{array}{c}\text { Decolorization } \\
\text { percentage }(\%)\end{array}$ & $\begin{array}{c}\mathrm{V}_{\text {initial decolorization }} \\
\mathrm{x} 10^{-3} \mathrm{~min}^{-1}\end{array}$ \\
\hline $2.2^{\mathrm{a}}$ & 595 & 0.600 & 2 & 61 & 4.22 \\
$7.0^{\mathrm{b}}$ & 591 & 0.850 & 3 & 62 & 5.12 \\
$10^{\mathrm{b}}$ & 589 & 0.900 & 4 & 37 & 4.57 \\
\hline
\end{tabular}

${ }^{\mathrm{a}} \mathrm{HCl} / \mathrm{KCl}$ solution; ${ }^{\mathrm{b}} \mathrm{B}-\mathrm{R}$ buffer. 
Although the color removal is important, the major practical interest in using the electrolytic method is complete mineralization of dye. In this context, experiments have been conducted by monitoring the total organic carbon (TOC) removal under the same operational conditions used for color removal. The TOC results obtained for aliquots of $2.5 \times 10^{-4} \mathrm{~mol} \mathrm{~L}^{-1} \mathrm{RB} 4$ in $\mathrm{HCl} / \mathrm{KCl}$ $\mathrm{pH} 2.2$ were submitted to electrolytic treatment during $120 \mathrm{~min}$. at potential of $-0.60 \mathrm{~V}$ and the degradation measurement obtained from the normalized equation: $\% \mathrm{TOC}=\left[\left(\mathrm{TOC}_{\text {initial }}-\mathrm{TOC}_{\text {final }}\right) / \mathrm{TOC}_{\text {initial }}\right] \mathrm{x} 100$. The results have shown $36 \%$ of the TOC removal, clearly indicating that the loss of the reactive group by reductive conditions confirming the previous results. At neutral and alkaline condition the values are smaller as hoped since no cleavage was detected in the molecule from IR and NMR results.

In summary, It is clear that cathodic reduction using reticulated glassy carbon electrode in aqueous solution could form the basis of convert the anthraquinone group but the technique is not efficient to promote the total degradation of reactive dye bearing this chromophore group. Nevertheless, this study demonstrates that a electrolytic reduction leads to a significant decolorization of the of Reactive Blue 4 dye at very acidic conditions of $\mathrm{HCl} / \mathrm{KCl}$. The semiquinone specie is generated preponderantly in acidic and neutral conditions, but the hydroquinone derivative is also the final product after some time in solution. Despite the decolorization of textile waste is based on optimal solution acceptable to treatment plants, ${ }^{1}$ analysis of our results have shown that the combination of other techniques is necessary before eventual discharge or recycling of process water. Others recalcitrant side-products could be generated, which could more toxic than the original dye. Nevertheless, the electrochemical reduction of RB4 dye could be a first step of decomposition of molecule.

\section{Acknowledgements}

Financial support from Capes, CNPq and Fapesp from Brazil are gratefully acknowledged.

\section{References}

1. Zollinger, H.; Color Chemistry: Syntheses, Properties and Applications of Organic Dyes and Pigments, $2^{\text {nd }}$ ed., V. C. H. Publisher: New York, 1991.

2. Venkataraman, K.; The Chemistry of Synthetic Dyes: The Reactive Dyes, Academic Press: New York, 1972, vol. VI.

3. Fewson, C. A.; Trends Biotechnol. 1988, 6, 148.
4. Clarke, E. A.; Anliker, R.; Handbook of Environmental Chemistry Part A - Antropogenic Compounds, ed. Hutizinger, O.: New York, 1980, vol. III.

5. Robinson, T.; McMullan, G.; Marchant, R.; Nigam, P.; Biores. Techn. 2001, 77, 247.

6. Lin, H. S.; Chen, M. L.; Water Res. 1997, 31, 868.

7. Sarasa, J.; Roche, M. P.; Ormad, M. P.; Gimeno, E., Puig, A.; Olivelleiro, J. L.; Water Res. 1998, 32, 2721.

8. Wu, J.; Eiteman, M. A.; Law, S. E.; J. Environ. Eng. 1998, 272.

9. Saunders, F. M.; Gould, P. J.; Southerland, R. C.; Water Res. 1983, 17, 1407.

10. Carriere, J.; Jones, J. P.; Broadbent, A. D.; Ozone Sci. Eng. 1993, 15, 189.

11. Pelegrini, R.; Zamora, P. P.; Andrade, A. R.; Reyes, J.; Duran, N.; Appl. Catal. B: Environm. 1999, 22, 83.

12. Luo, J.; Hepel, M.; Electrochim. Acta 2001, 46, 2913.

13. Szpyrkowicz, L.; Juzzolino, C.; Daniele, S.; Ind. Eng. Chem. Res. 2000, 39, 3241.

14. Szpyrkowicz, L.; Juzzolino, C.; Kaul, S. N.; Water Res. 2001, 35, 2129.

15. Naumczyk, J.; Szpyrkowicz, L.; Zilio, G. F.; Water Sci. Technol. 1996, $11,17$.

16. Zanoni M. V. B.; Fogg A. G.; Barek. J.; Zima. J.; Anal. Chim. Acta 1997, 349. 101.

17. Zanoni, M. V. B.; Fogg, A. G.; Guaratini, C. C. I.; Dyes Pigments 2001, 50, 211.

18. Zanoni, M. V. B.; Guaratini, C. C. I.; Fogg, A. G.; Electroanal. 2001, 13, 1535.

19. Zanoni, M. V. B.; Carneiro, P.; Furlan, M.; Guaratini, C. C. I.; Fogg, A. G.; Anal. Chim. Acta 1999, 385, 385.

20. Deng, N.; Wu, F.; Luo, F.; Liu, Z.; Chemosphere 1997, 35, 2697.

21. Deng, N.; Wu, F.; Shizhong, T.; Fang, T.; Chemosphere 1997, 34, 2725.

22. Deng, N.; Wu, F.; Shizhong, T.; Fang, T.; Chemosphere 1996, $33,547$.

23. Deng, N; Wu, F.; Xiao, M.; Wu, X.; Water Res. 2000, 34, 2408.

24. Baizer, M. M.; Lund, H.; Organic Electrochemistry an Introduction and a Guide, $2^{\text {nd }}$ ed., Marcel Dekker Inc.: New York, 1983.

25. Nicholson, R. S.; Shain, I.; Anal. Chem. 1964, 36, 706.

26. Nicholson, R. S.; Shain, I.; Anal. Chem. 1965, 37, 178.

27. Silverstein, R. M.; Webster, F. X.; Spectrometric Identification of Organic Compounds, Wiley: New York, 1998.

28. Ingnjatovic, L. M.; Markovic, D.A.;Veselinovìc, D.S.; Besic, B.R.; Electronal. 1993, 5, 529.

Received: February 3, 2003

Published on the web: July 21, 2004

FAPESP helped in meeting the publication costs of this article. 